\title{
Investigation into Constitutive Equation and Hot Compression Deformation Behavior of 6061 Al Alloy
}

\author{
Xiang ZHANG, Xiaoxi WANG, Dekun ZHANG
}

\begin{abstract}
Hot compression tests of $6061 \mathrm{Al}$ alloy were applied under the Gleeble- 3500 system at temperature range of $300-450{ }^{\circ} \mathrm{C}$ and strain rate range of $0.01-10 \mathrm{~s}^{-1}$. The true stress-strain curves of $6061 \mathrm{Al}$ alloy were acquired and the flow stress was recorded and corrected. The associated microstructure of $6061 \mathrm{Al}$ alloy after hot deformation process was observed. The results suggest that the stress level of $6061 \mathrm{Al}$ alloy during hot compression process decreases with increasing compression temperature and decreasing strain rate. Arrhenius equation and the Zener-Hollomon parameter in the hyperbolic sine-type equation were utilized in present research to formulate the constitutive equation of $6061 \mathrm{Al}$ alloy. The microstructure after hot deformation consists of elongated grains and the dynamic recovery of $6061 \mathrm{Al}$ alloy occurs during hot compression. However, for the alloy deformed at low $Z$ value, the existence of newly refined grains around the serrated grain boundaries indicates the occurrence of partial dynamic recrystallization.
\end{abstract}

Keywords: constitutive equation; flow stress; hot compression deformation; microstructure; $6061 \mathrm{Al}$ alloy

\section{INTRODUCTION}

As a promising engineering material, aluminum and its alloys have attracted a lot of attention over the past decades [1-2]. As an Al-Mg-Si wrought Al alloy, 6061 Al alloy can be deformed and strengthened by a proper heat treatment process. With the combination of medium strength, high fracture toughness, excellent corrosion resistance, good weldability and low cost [3], it is wildly used in many areas such as vehicles, electronic applications and other industries, where lightening the structures is considered as an essential goal to improve the fuel efficiency and thus mitigate the impact on environment.

Due to its incompetent workability at the room temperature, $6 \times \times \times$ series Al alloy is mainly applied in thermoforming procedures. Flow stress is critical for characterizing the plastic yielding capability of metal materials [4-6]. The mechanic properties of Al alloys are closely related to their microstructures and will be affected by the degree of hot working. Many reports [7-10] have shown that manipulated by forming heat, strain-rate and deformation degree, work-hardening and dynamic softening phenomenon decide together on the flow behaviour's complication during thermal forming process. Moreover, softening mechanisms and microstructure development also ride directly on the primary deformation condition. A lot of previous studies are mainly focused on $2 \times \times \times$ and $7 \times \times \times$ series Al alloys, while insufficient survey on thermal formability of $6061 \mathrm{Al}$ alloy has been implemented and published so far.

In this paper, we try to conduct the isothermal compression experiments of $6061 \mathrm{Al}$ alloy through various compression temperatures and different strain rates, to modify the obtained flow stress in an easy and effective way, and furthermore, to extensively study the hot deformation behavior of $6061 \mathrm{Al}$ alloy based on stress strain curve establishing, constitutive model building-up and microstructure observation. The primary target of present research was to obtain basic knowledge of thermoforming behaviour of $6061 \mathrm{Al}$ alloy, so as to optimize the thermoforming process parameters and to control associated microstructures.

\section{EXPERIMENT}

The experiments were carried out on as-cast homogenized $6061 \mathrm{Al}$ alloy with main element components of $0.78 \% \mathrm{Si}, 1.0 \% \mathrm{Mg}, 0.27 \% \mathrm{Cu}, 0.12 \% \mathrm{Fe}$, $0.05 \% \mathrm{Cr}$ (wt. \%). Cylindrical specimens (diameter: 10 $\mathrm{mm}$, length: $15 \mathrm{~mm}$ ) were obtained from a round bar ingot (diameter: $120 \mathrm{~mm}$, length: $1000 \mathrm{~mm}$ ) by WEDM, the microstructure of which before deformation is shown in Fig. 1. As the figure shows, the homogeneous and coarse grains having a mean grain size of approximately $55 \mu \mathrm{m}$ are obvious and visualized.

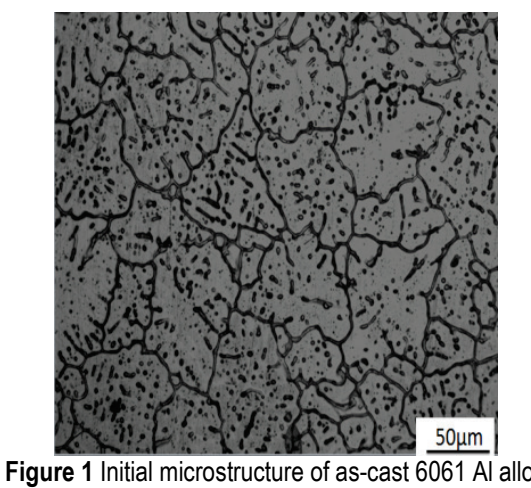

Table 1 Experimental parameters.

\begin{tabular}{|c|c|c|c|c|}
\hline Temperature $/{ }^{\circ} \mathrm{C}$ & 300 & 350 & 400 & 450 \\
\hline Strain rate $/ \mathrm{s}^{-1}$ & 0.01 & 0.1 & 1 & 10 \\
\hline
\end{tabular}

The isothermal deformation compression tests proceed step by step on a Gleeble-3500 experimental machine, setting experimental parameters as shown in Tab. 1. To reduce the detrimental effect of friction during compression tests, fine graphite and engine oil composite, our ideal lubricant selection, goes towards both ends of specimens and meanwhile tantalum tablets are used to isolate samples and models as well. Under each kind of experimental condition mentioned above, resistance-heat of the specimens (heating rate: $1{ }^{\circ} \mathrm{C} / \mathrm{s}$ ) to designated temperature before compression, is held for $300 \mathrm{~s}$ by thermocouple-feedback control method and we gain an even deforming temperature. When the deformation of the 
sample reaches 0.6 , the deforming microstructure is obtained by water quenching.

Test data are automatically recorded and saved by computer. The processed specimens need to be sectioned along central line direction and parallel to compression axis which is used for microstructure observation on an OLYMPUS GX51 metallographic microscope and a SEM equipment (JSM-7001F) with EBSD system.

\section{FRICTION CORRECTION OF FLOW STRESS}

Friction plays a critical part in metal forming processes [11]. During high temperature deformation tests, appropriate lubrication measures can undermine the interfacial friction to a minimum value. However, it is impossible to eliminate the friction completely. When the strain approaches a certain value, the specimen yields inhomogeneous deformation, leading to the alteration of constant strain rate. Due to the friction at specimen/platen interfaces, barreling is obviously observed at the cylindrical specimens after high temperature deformation tests, which is shown in Fig. 2, indicating that nature of experiment is destroyed.
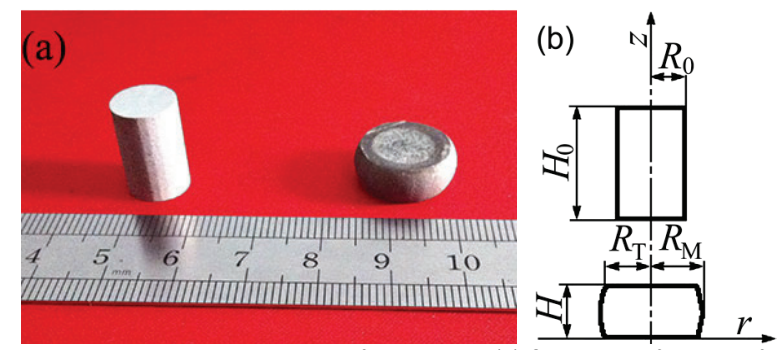

Figure 2 The schematic diagram of specimens: (a) Cylinders before and after compression tests; (b) Schematic of hot compression specimen.

To quantitatively evaluate the influence of friction on flow behaviour of the alloys, the barreling coefficient is introduced as shown in the following formula [12].

$$
B=\frac{H_{\mathrm{f}} D_{\mathrm{f}}^{2}}{H_{0} D_{0}^{2}}
$$

where $B$ is the barreling coefficient and increases with the increase of barreling, $H_{\mathrm{f}}$ is final specimen's height, $D_{\mathrm{f}}$ is final specimen's diameter measured at the middle length of the specimen, $D_{0}$ and $H_{0}$ are diameter and height of undeformed specimen, respectively.

When the $B$ value is between 1 and 1.1 , the deviation between the measured value of flow stress and the true value is small, and there is no need for friction correction. While $B>1.1$, it means that flow stress is seriously affected by friction, and friction correction is necessary to be carried out.

Table 2 Calculated values of $\mathrm{B}$ under different deformation conditions

\begin{tabular}{|c|c|c|c|c|}
\hline \multirow{2}{*}{ Strain rate $/ \mathrm{s}^{-1}$} & \multicolumn{4}{|c|}{ Temperature $/{ }^{\circ} \mathrm{C}$} \\
\cline { 2 - 5 } & 300 & 350 & 400 & 450 \\
\hline 0.01 & 1.069 & 1.124 & 1.098 & 1.125 \\
\hline 0.1 & 1.082 & 1.084 & 1.099 & 1.111 \\
\hline 1 & 1.065 & 1.102 & 1.100 & 1.118 \\
\hline 10 & 1.065 & 1.103 & 1.097 & 1.106 \\
\hline
\end{tabular}

Tab. 2 gives the calculated bulging coefficient $(B)$ in several different strain rates and temperatures in present study. It can be seen that in most cases, $B$ is larger than 1.1, so friction correction is necessary especially at high temperatures.

A simple and effective method was employed to correct the errors in flow stress caused by friction. Based on deformation power rule, the true flow stress could be calculated from the upsetting deformation force [13]:

$$
\sigma_{\mathrm{f}}=\frac{F_{\mathrm{i}}}{\frac{\pi}{4} D^{2}\left(1+\frac{m}{3 \sqrt{3}} \frac{D}{l}\right)}
$$

where $\sigma_{\mathrm{f}}$ is the flow stress after friction correction, $D, l$, and $F_{\text {i }}$ are instantaneous diameter, instantaneous height and instantaneous load of the specimen during hot compression process, respectively. Parameter $m$ stands for the constant friction coefficient.

Furthermore, after obtaining the max radius and the height of deformed cylindrical specimen, the constant friction coefficient $(m)$ will be determined by the given equation put forward by Ebrahimi [14]:

$$
m=\frac{(R / H) b}{(4 / \sqrt{3})-(2 b / 3 \sqrt{3})}
$$

where

$$
b=4 \frac{\Delta R}{R} \frac{H}{\Delta H}, R=R_{0} \sqrt{\frac{H_{0}}{H}} \text { and } R_{\mathrm{T}}=\sqrt{3 \frac{H_{0}}{H} R_{0}^{2}-2 R_{\mathrm{M}}^{2}} .
$$

In Eq. (3), $R_{\mathrm{M}}$ and $R_{\mathrm{T}}$ refer to the max and top radius of deformed cylindrical specimen. $\triangle R$ represents the difference in value between the former two values of radius. $\triangle H$ is the reduction in height of cylindrical specimen before and after compression, $H$ is the height of compressed cylindrical specimen, $R_{0}$ and $H_{0}$ are original radius and height of cylindrical specimen, respectively. Fig. 2(b) shows schematic diagram of specimens before and after high temperature deformation experiment.

\section{RESULTS AND DISCUSSION \\ 4.1 True Stress-Strain Curves}

Fig. 3 gives actual stress-strain curves (presented in solid lines) of 6061Al alloy obtained during high temperature compression experiments under different deformation conditions in present study. For comparison, the actual stress-strain curves obtained from the corrected flow stress (presented by dashed lines) are also presented.

It can be observed that under each given condition, at the beginning of hot deformation, there is little difference between two curves. However, two curves vary greatly while the flow stress achieves the maximum value, indicating that the influence of friction on flow stress of $6061 \mathrm{Al}$ alloy is increasing and cannot be ignored. In addition, we can apparently observe that the value of corrected flow stress is always smaller than the experimental one. 


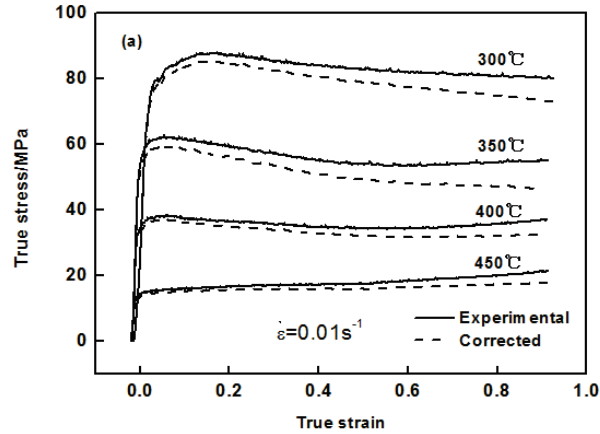

(a)

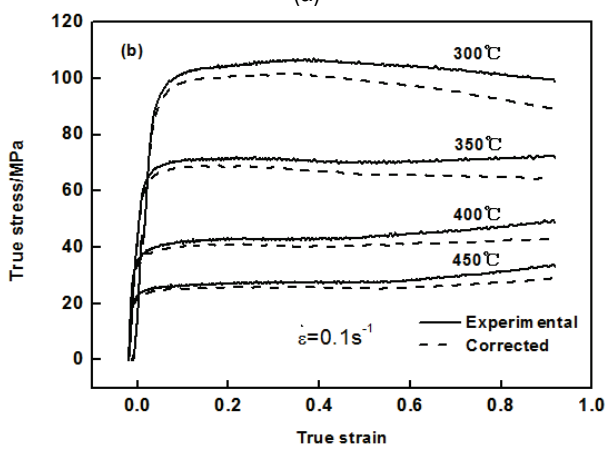

(b)

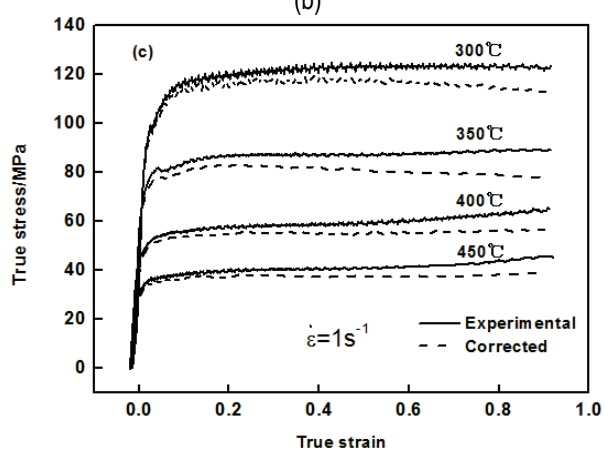

(c)

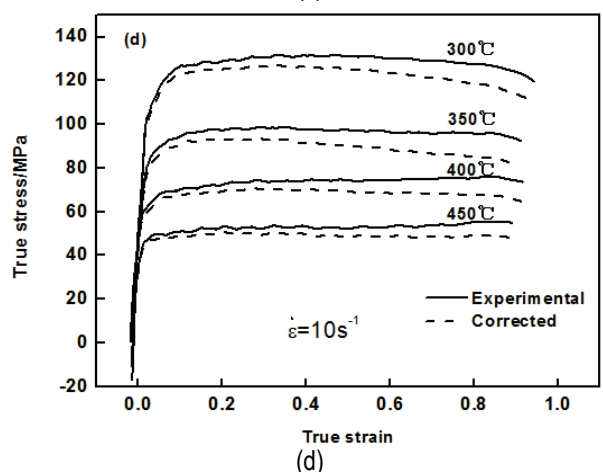

Figure 3 True stress-strain curves of $6061 \mathrm{Al}$ alloy: (a) $\dot{\varepsilon}=0.01 \mathrm{~s}^{-1}$; (b) $\dot{\varepsilon}=0.1 \mathrm{~s}^{-1}$; (c) $\dot{\varepsilon}=1 \mathrm{~s}^{-1}$; (d) $\dot{\varepsilon}=10 \mathrm{~s}^{-1}$

As shown in Fig. 3, for each curve, in the early deforming stages, flow stress raises dramatically as the increasing strain, matching the work hardening phenomenon caused by dislocation densities soaring. After early deforming stages, there is a max stress achieved under certain strain by the curves following through constant or slightly declining variety with the increasing strain, treated as steady state flow behaviour. This could be ascribed to the emergence of dynamic softening in the process of thermal deformation. Therefore the flow stress cannot keep rising owing to that weakens work-harden behaviour. Actually, the work-hardenning and the dynamic restoration will emerge concurrently in the material during the thermo mechanical processing [15], leading a dynamic equilibrium eventually. The equilibrium contributes to the relatively constant dislocation density and steady state of flow stress. In the remainder of present study, we provided a detailed discussion about true softening mechanism by comparative analysis between calculated activation energy and microstructure test.

It could be also found from Fig. 3 that during hot compression, deforming temperature and the strain rate lay great emphasis on flow behaviour of $6061 \mathrm{Al}$ alloys. When the strain rate is constant, due to the intense heat activation process and the emergence of dynamic softening, the maximum stress reduces as the increasing deforming temperature, indicating that the experimental $6061 \mathrm{Al}$ alloys are sensitive materials having positive strain rate. This may be bound to the fact of dislocation generation and multiplication. In specific, as the rise of the strain rate, due to the deforming time is very short there is no sufficient time for the occurrence of dynamic softening. Therefore, the mechanisms of work-hardenning play the crucial role, causing the dramatic increase of flow stress.

\subsection{Constitutive Equations}

For metallic material, hot compression could be regarded as a process of thermal activation, and strain rate $\dot{\varepsilon}$ is tightly bound up with temperature $T$, deforming activation energy $Q$ and flow stress $\sigma$. Previous research reports prove that high prediction accuracy is available in describing the flow stress when taking Arrhenius model into consideration, especially at elevated temperature.

The power rule (Eq. (4)) is applicable to small stress values $(\alpha \sigma<0.8)$, while exponential rule (Eq. (5)) works on large stress values $(\alpha \sigma>1.2)$ :

$$
\begin{aligned}
& \dot{\varepsilon}=A_{1} \sigma^{n_{1}} \exp \left(-\frac{Q}{R T}\right), \\
& \dot{\varepsilon}=A_{2} \exp (\beta \sigma) \exp \left(-\frac{Q}{R T}\right),
\end{aligned}
$$

where $A_{1}, A_{2}, n_{1}$ and $\beta$ are the parameters representing the properties of materials themselves, $\dot{\varepsilon}$ is the strain rate, $\sigma$ is the maximum flow stress, $Q$ is the activation energy of high temperature compression, $R$ is the gas-constant, and $T$ is the absolute temperature.

Moreover, hyperbolic sinusoidal formula (Eq. (6)) put forward in Reference [16], is considered to be a more general template suitable and compatible with broad stress ranges, particularly for characterizing high temperature forming behaviour of $\mathrm{Al}$ alloys:

$\dot{\varepsilon}=A \cdot[\sin h(\alpha \sigma)]^{n} \exp \left(-\frac{Q}{R T}\right)$

$A$ and $n$ are the parameters representing the properties of materials themselves. As a supplementary adjustable factor, $\alpha$ is a stress multiplier (where $\alpha=\beta / n_{1}$ ).

During Thermal compression process of $\mathrm{Al}$ alloys, the strain rate is controlled by thermal activation. Furthermore, as a temperature compensating strain rate index, the Zener- 
Hollomon parameter $Z$ can be used to express Arrhenius model $[17,18]$.

$$
Z=\dot{\varepsilon} \exp \left(\frac{Q}{R T}\right)
$$

By introducing Eq. (7) into Eq. (6), $Z$ can also be expressed as a hyperbolic sinusoidal relation.

$Z=\dot{\varepsilon} \exp \left(\frac{Q}{R T}\right)=A \cdot[\sinh (\alpha \sigma)]^{n}$

Using the hyperbolic sinusoidal rule, the flow stress $\sigma$ can also be rewritten by $Z$ parameter.

$$
\sigma=\frac{1}{\alpha} \ln \left\{\left(\frac{Z}{A}\right)^{\frac{1}{n}}+\left[\left(\frac{Z}{A}\right)^{\frac{2}{n}}+1\right]^{\frac{1}{2}}\right\}
$$

Material constants of $6061 \mathrm{Al}$ alloy required for Arrhenius modeling are calculated by adopting the natural logarithmic values for Eq. (4) and Eq. (5), respectively.

$$
\begin{aligned}
& \ln \dot{\varepsilon}=\ln A_{1}-\left(\frac{Q}{R T}\right)+n_{1} \ln \sigma \\
& \ln \dot{\varepsilon}=\ln A_{2}-\left(\frac{Q}{R T}\right)+\beta \sigma
\end{aligned}
$$

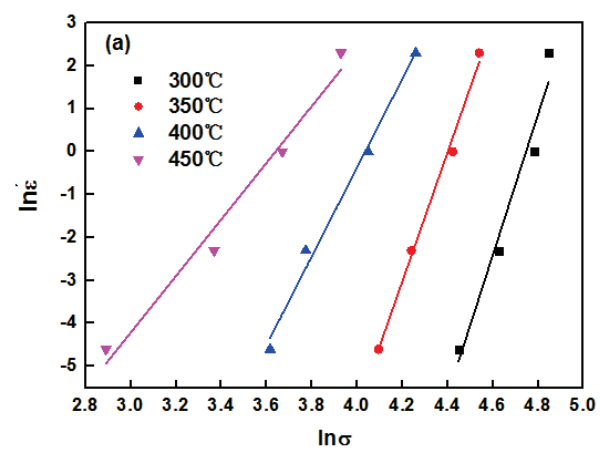

(a)

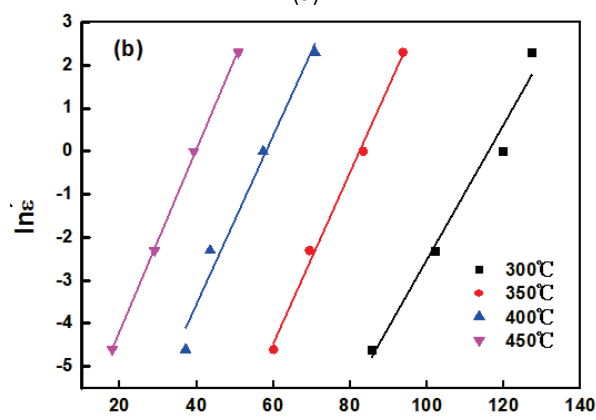

(b)

Figure 4 Relationship between strain rate and flow stress at different deformation temperature: (a) $\ln \dot{\varepsilon}-\ln \sigma$; (b) $\ln \dot{\varepsilon}-\sigma$

Hence, the values of $n_{1}$ and $\beta$ can be easily acquired by linear regression. Then, the maximum stress and its strain rates at different temperatures were used to describe the relations of $\ln \dot{\varepsilon}-\ln \sigma$ and $\ln \dot{\varepsilon}-\sigma$, as plotted in Figs. 4(a) and $4(\mathrm{~b})$, respectively.

From Fig. 4, the flow stresses acquired from hot deformation are well fitted with a set of parallel-lines. Based on Eqs. (10) and (11), $n_{1}$ is taken as the average value of the slope of the parallel-lines in Fig. 4(a) at low stress, while $\beta$ is taken as the average value of the slope of the parallel-lines in Fig. 4(b) at high stress. As a result, the calculated mean values of $n_{1}$ and $\beta$ are 8.46535 and 0.17815 , respectively. Therefore, it is easy to calculate the value of $\alpha$ to be 0.02104 .

It can be assumed that thermal compression activation energy $Q$ is independent of compression temperature $T$. By adopting the natural logarithmic values for Eq. (6), the following expression is derived:

$\ln \dot{\varepsilon}=\ln A-\left(\frac{Q}{R T}\right)+n \ln [\sinh (\alpha \sigma)]$

As can be seen in Eq. (12), $n$ is the mean slope of four fitting lines in Fig. 5.

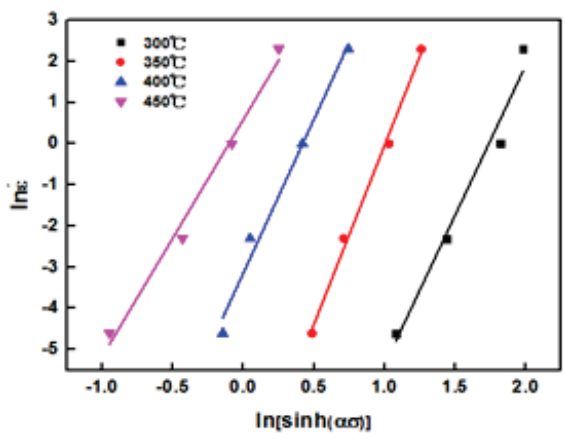

Figure 5 Relationship between $\ln [\sinh (\alpha \sigma)]$ and $\ln \dot{\varepsilon}$

At the same time, under the given strain rate, thermal compression $Q$ can be supposed to be constant within a particular temperature range, so that $Q$ can be described by the following equation.

$Q=\left.\left.R \frac{\partial \ln \dot{\varepsilon}}{\partial \ln [\sinh (\alpha \sigma)]}\right|_{\mathrm{T}} \frac{\partial \ln [\sinh (\alpha \sigma)]}{\partial(1 / T)}\right|_{\dot{\varepsilon}}=R n S$,

where $S$ represents the mean slope of $\ln [\sinh (\alpha \sigma)]-1000 / T$ plot. With the relevant numerical value substituted ( $T$ and $\sigma)$, it is easy to get relationships of $\ln [\sinh (\alpha \sigma)]-1000 / T$, as shown in Fig. 6.

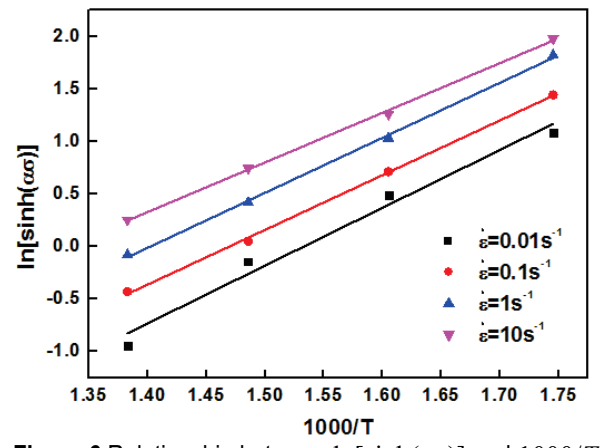

Figure 6 Relationship between $\ln [\sinh (\alpha \sigma)]$ and 1000/T 
Thus, the values of these two factors are determined as 7.3005925 and 5.1779275, respectively. Therefore, based on Eq. (13), the thermal compression activation energy $Q$ of $6061 \mathrm{Al}$ alloy can be obtained, and it is around 314.304 $\mathrm{kJ} / \mathrm{mol}$.

Taking the natural logarithm of both sides of Eq. (8) yields:

$$
\ln Z=\ln A+n \ln [\sinh (\alpha \sigma)]
$$

Then, according to Eq. (7), calculate $Z$ value by the obtained $Q$ value. As you can see in Tab. 3, with the strain rate rising and the compression temperature falling, the values of $Z$ parameter increase significantly, consistent with the trend of the maximum flow stress (seen in Fig. 3).

Table $3 \ln Z$ values at different compression conditions

\begin{tabular}{|c|c|c|c|c|}
\hline \multirow{2}{*}{ Strain rate $/ \mathrm{s}^{-1}$} & \multicolumn{4}{|c|}{ Temperature $/{ }^{\circ} \mathrm{C}$} \\
\cline { 2 - 5 } & 300 & 350 & 400 & 450 \\
\hline 0.01 & 61.37 & 56.07 & 51.56 & 47.68 \\
\hline 0.1 & 63.67 & 58.37 & 53.87 & 49.98 \\
\hline 1 & 65.97 & 60.68 & 56.17 & 52.28 \\
\hline 10 & 68.27 & 62.98 & 58.47 & 54.58 \\
\hline
\end{tabular}

Fig. 7 illustrates the relations of $\ln Z$ and $\ln [\sinh (\alpha \sigma)]$ of the alloy at various compression conditions. The coefficient of correlation is as high as 0.991 , indicating a good linear relation between $\ln Z$ and $\ln [\sinh (\alpha \sigma)]$. Therefore, it is not hard to calculate that the values of $\ln A$ and $n$ are 53.25765 and 7.23209, respectively.

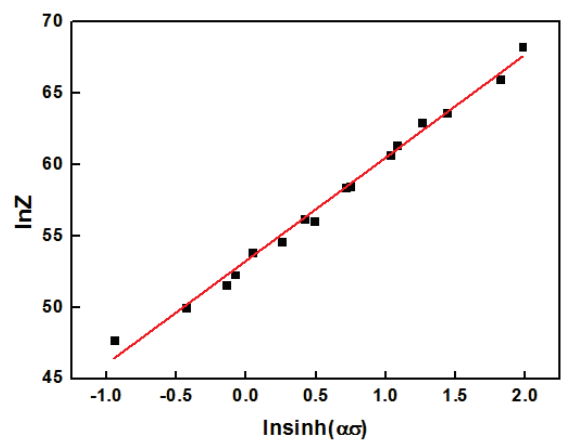

Figure 7 Relations between Zener-Hollomon parameter and flow stress

Finally, with the values of $A, \alpha, n$ and $Q$ substituted into Eq. (6), the thermal compression constitutive equation of $6061 \mathrm{Al}$ alloy can be represented in a hyperbolic sinusoidal function as follows, where $Q$ is $314.304 \mathrm{~kJ} / \mathrm{mol}$.

$$
\begin{aligned}
& \dot{\varepsilon}=1.34742 \times 10^{23}[\sinh (0.02104 \sigma)]^{7.23209} \times \\
& \times \exp \left(\frac{-314.304 \times 10^{3}}{R T}\right)
\end{aligned}
$$

Based on the above Eq. (9), the flow stress of $6061 \mathrm{Al}$ alloy in the process of hot deformation can be also expressed by Zener-Hollomon parameter $Z$ :

$$
\begin{aligned}
& \sigma=47.5285 \ln \left\{\left[Z /\left(1.34742 \times 10^{23}\right)\right]^{1 / 7.23209}+\right. \\
& \left.+\left\{\left[Z /\left(1.34742 \times 10^{23}\right)\right]^{2 / 7.23209}+1\right\}^{1 / 2}\right\}
\end{aligned}
$$

where $Z=\dot{\varepsilon} \exp \left(\frac{314.304 \times 10^{3}}{R T}\right)$.

To test the reliability of established constitutive model for $6061 \mathrm{Al}$ alloy in the present study, compare experimental flow stress with predicted value based on Arrhenius formula calculated from Eq. (16) was carried out, (seen in Fig. 8). Obviously, it was easy to see the flow stresses calculated from our established constitutive equation of Eq. (16) agree well with the experimental values. The maximum average deviation for flow stress prediction is about $1.74 \%$, which confirms that in this work, Arrhenius formula is capable to calculate the flow stress of $6061 \mathrm{Al}$ alloy at high-temperature with the high accuracy and reliability.

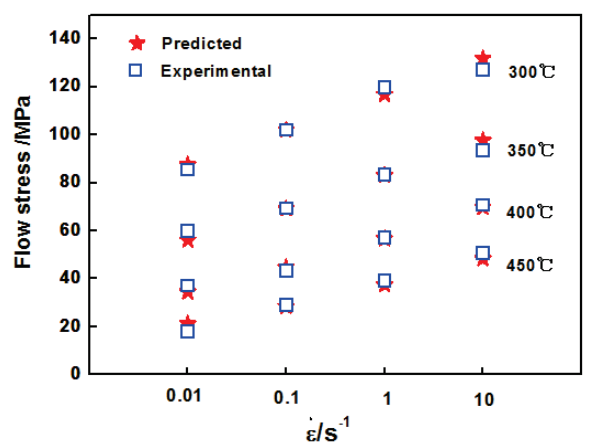

Figure 8 Comparison of predicted flow stress with that of experimental at various deformation conditions

\subsection{Microstructure Evolution}

In various deformation conditions, the metallographic observations of $6061 \mathrm{Al}$ alloy are illustrated in Fig. 9. This indicates that after being deformed, the grains were compressed flat at the direction vertical to the compression axis. At lower temperatures $\left(350{ }^{\circ} \mathrm{C}\right.$ and $\left.400{ }^{\circ} \mathrm{C}\right)$, microstructure mainly consists of elongated grains within shear bands representing that the dynamic recovery is considered to be the predominant soft mechanism. With the rise of deformation temperature, the elongated grains coarsened and some newly refined grains come into being around the vicinity of serrated grain boundaries (seen in Fig. 9(c)), indicating that low $Z$ value would promote partial dynamic re-crystallization. While at elevated temperature but high strain-rate, the stress strain diagram shows a higher maximum stress and more strain hardening (seen in Fig. 3(c)). As a result of rapid deformation, the sliding and climbing of dislocations are hindered. Correspondingly, there may not be sufficient time for the stored deformation energy to be released and the process of dynamic recrystallization is not easy to occur, as shown in Fig. 9(d).

What can be also discovered from EBSD image as shown in Fig. 10 is that while alloy processed at $450{ }^{\circ} \mathrm{C}$ and $0.01 \mathrm{~s}^{-1}$ strain rate, there exists obviously dynamic recrystallization with grain and sub-grain coarsening. Moreover, the formation of serrated grain boundaries indicates that dis-continuous dynamic re-crystallization occurs at this time. Therefore, the transformation from dynamic recovery to partial dynamic re-crystallization depends upon the predominant soft mechanism at elevated temperature or low strain rate (at low $Z$ value). 


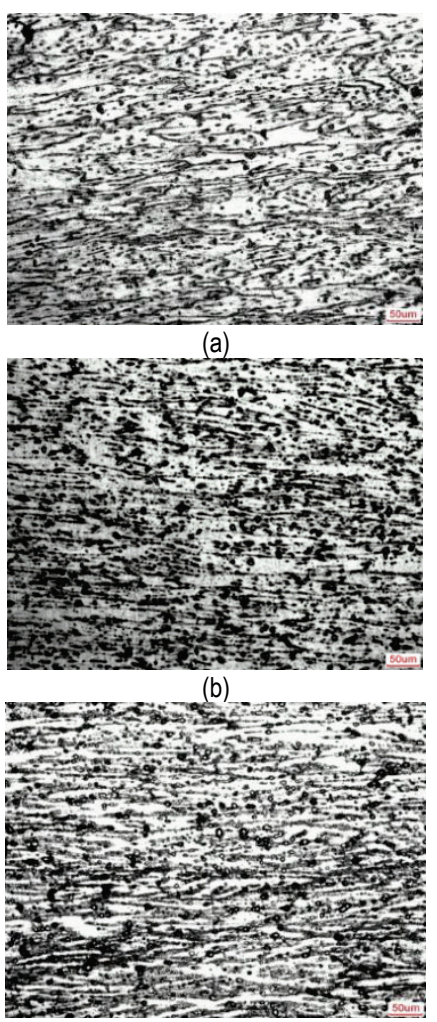

(c)

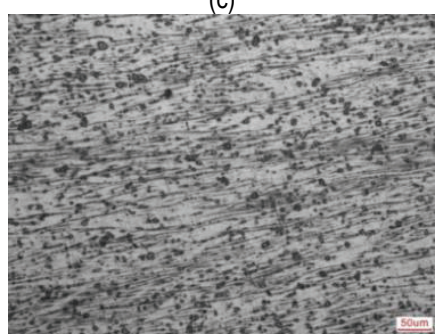

(d)

Figure 9 The microstructures of $6061 \mathrm{Al}$ alloy deformed under different deformation conditions: (a) $350^{\circ} \mathrm{C}, 0.01 \mathrm{~s}^{-1}$; (b) $400{ }^{\circ} \mathrm{C}, 0.01 \mathrm{~s}^{-1}$; (c) $450{ }^{\circ} \mathrm{C}$ $0.01 \mathrm{~s}^{-1} ;$ (d) $450{ }^{\circ} \mathrm{C}, 10 \mathrm{~s}^{-1}$

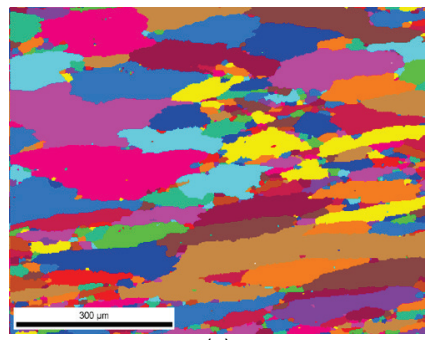

(a)

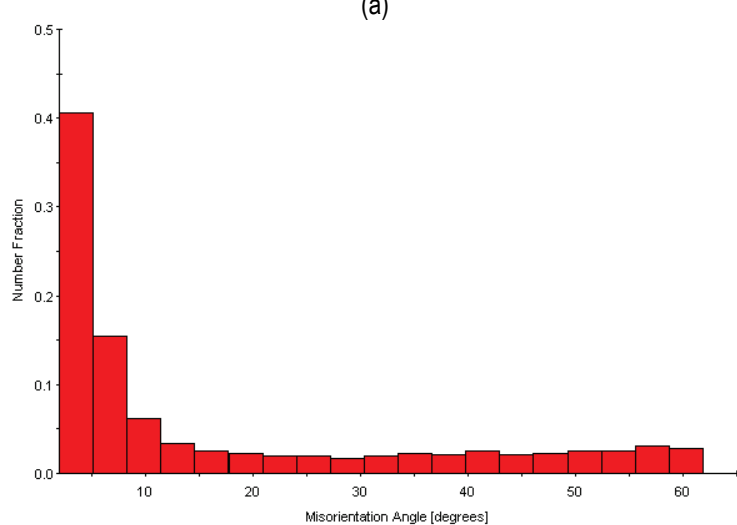

(b)

Figure 10 EBSD image of $6061 \mathrm{Al}$ alloy deformed at $450{ }^{\circ} \mathrm{C}, 0.01 \mathrm{~s}^{-1}$ : (a) Grain map (b) misorientation distribution
In general, owing to its elevated stacking-fault energy, dynamic re-crystallization of $\mathrm{Al}$ alloys is not easy to take place. In the present work, when decreasing strain rate or increasing compression temperature, the stress strain plot illustrates a lower maximum stress and displays gradual softening with the sub-grains occurring, as shown in Fig. 3(a).

Due to the full movement of metallic atoms and dislocations, sub-grains continue to merge. At the same time, the low-angle grain boundary is continuously changed into the large-angle grain boundary by dislocation annihilation [20-22]. Consequently, the number of blocking dislocations is reduced and the occurrence of dynamic recrystallization tends to be more likely. In conclusion, for the alloy processed at elevated deformation temperature and low-strain rate, the tendency of dynamic recrystallization enhanced.

\section{CONCLUSIONS}

(1) A simple and effective method was employed to correct the errors in flow stress caused by friction effect. When the flow stress achieves the maximum value, the influence of friction on flow behavior is increasing and cannot be ignored. The corrected flow stress of $6061 \mathrm{Al}$ alloy is always lower than experimental value.

(2) The compression temperature and the strain rate mainly dominate flow behaviour of $6061 \mathrm{Al}$ alloy during hot compression. As compression temperature declines and the strain rate raises, the steady flow stress elevates significantly. This can be validated by a ZenerHollomon parameter in the hyperbolic sinusoidal function, with the thermal compression activation energy of $314.304 \mathrm{~kJ} / \mathrm{mol}$.

(3) The processed microstructures consist of elongated grains and dynamic recovery is the primary cause of flow softening for $6061 \mathrm{Al}$ alloy. However, for the alloy processed under small $\mathrm{Z}$ value, a few fine re-crystallized grains occurred at the vicinity of serrated grain boundaries and partial dynamic recrystallization occurs.

\section{Acknowledgements}

This study was funded by the Youth Science and Technology Talents "Support Project" (2018202) of Jiangsu Science and Technology Association, the Natural Science Foundation of Jiangsu Higher Education Institutions of China (17KJB430031) and the project of Jiangsu provincial Six Talent Peaks (GDZB-127).

\section{REFERENCES}

[1] Liu, J. \& Xie, S. (2011). Development history, present situation and trend of aluminum and Al alloy processing industry. Application and development of Al alloy, $1^{\text {st }}$ ed, Beijing, Metallurgical Industry Press, 49-62. (in Chinese)

[2] Mcqueen, H. J., Spigarelli, S., Kassner, M. E., \& Evangelista, E. (2011). Aluminum and Its Alloys, Hot deformation and processing of Al alloys, $1^{\text {st }}$ ed, New York, CRC Press, 1-10.

[3] Shokuhfar, A. \& Nejadseyfi, O. (2014). A comparison of the effects of severe plastic deformation and heat treatment on the tensile properties and impact toughness of Al alloy 6061 . Mater. Sci. Eng. 594A, 140-148. https://doi.org/10.1016/j.msea.2013.11.067 
[4] Jin, N., Zhang, H., Han, Y., Wu, W., \& Chen, J. (2009). Hot deformation behaviour of $7150 \mathrm{Al}$ alloy during compression at elevated temperature. Mater. Charact., 60, 530-536. https://doi.org/10.1016/j.matchar.2008.12.012

[5] Huang, X., Zhang, H., Han, Y., Wu, W., \& Chen, J. (2010). Hot deformation behaviour of $2026 \mathrm{Al}$ alloy during compression at elevated temperature. Mater. Sci. Eng., 527A, 485-490. https://doi.org/10.1016/j.msea.2009.09.042

[6] Rokni, M. R., Zarei-Hanzaki, A., Roostaei, A. A., \& Abedi, H. R. (2011). An investigation into the hot deformation characteristics of $7075 \mathrm{Al}$ alloy. Mater. Des. 32, 2339-2344. https://doi.org/10.1016/j.matdes.2010.12.047

[7] Chen, S., Chen, K., Jia, L., \& Peng, G. (2013). Effect of hot deformation conditions on grain structure and properties of 7085 Al alloy, Trans. Nonferrous. Metal. Soc. China, 23, 329-334. https://doi.org/10.1016/S1003-6326(13)62465-6

[8] Deng, Y., Yin, Z., \& Huang, J. (2011). Hot deformation behaviour and microstructural evolution of homogenized $7050 \mathrm{Al}$ alloy during compression at elevated temperature. Mater. Sci. Eng, 528A, 1780-1786. https://doi.org/10.1016/j.msea.2010.11.016

[9] Chen, S., Chen, K., Peng, G., Chen, X., \& Ceng, Q. (2012). Effect of heat treatment on hot deformation behaviour and microstructure evolution of $7085 \mathrm{Al}$ alloy. J. Alloys. Compd, 537, 338-345. https://doi.org/10.1016/j.jallcom.2012.05.052

[10] Lin, Q., Dong, W., Li, Y., Zhang, H., \& Wang, Z. (2014). Microstructure simulation of $2519 \mathrm{Al}$ alloy in multi-pass hot compression process, Procedia Engineering, 81, 1259-1264. https://doi.org/10.1016/j.proeng.2014.10.107

[11] Soheil, S. (2010). A note on "Barrel Compression Test": A method for evaluation of friction. Comp. Mater. Sci, 49, 435438. https://doi.org/10.1016/j.commatsci.2010.04.047

[12] Roebuck, B., Lord, J. D., Brooks, M., Loveday, M. S., Sellars, C. M., \& Evans, R. W. (2006). Measurement of flow stress in hot axisymmetric compression tests. Mater. High Temp, 23, 59-83. https://doi.org/10.1179/mht.2006.005

[13] Zhang, W. \& Zhang, S. (2006). Correction of hot compression test data and constitutive equation of NiTi alloy. ActaMetall Sin (Engl Lett), 42, 1036-1040. (in Chinese)

[14] Ebrahimi, R. \& Najafizadeh, A. (2004). A new method for evaluation of friction in bulk metal forming. J. Mater. Process. Technol, 152, 136-143. https://doi.org/10.1016/j.jmatprotec.2004.03.029

[15] Chen, L., Zhao, G., \& Yu, J. (2015). Hot deformation behaviour and constitutive modeling of homogenized 6026 Al alloy. Mater. Des, 74, 25-35. https://doi.org/10.1016/j.matdes.2015.02.024

[16] Sellars, C. M. \& McTegart, W. J. (1966). On the mechanism of hot deformation. ActaMetall, 14, 1136-1138. https://doi.org/10.1016/0001-6160(66)90207-0

[17] Zener, C. \& Hollomon, J. H. (1944). Effect of strain rate upon the plastic flow of steel. J. Appl. Phys, 15, 22-32. https://doi.org/10.1063/1.1707363

[18] Winston, A., Wong, G., \& Jonas, J. J. (1968). Aluminum extrusion as a thermally activated process. Trans. Met. Soc. AIME, 242, 2271-2280.

[19] Asgharzadeh, H., Simchi, A., \& Kim, H. S. (2012). Dynamic restoration and microstructural evolution during hot deformation of a P/M Al 6063 alloy. Mater. Sci. Eng, 542A, 56-63. https://doi.org/10.1016/j.msea.2012.02.031

[20] Sun, Z., Zheng, L., \& Yang, H. (2014). Softening mechanism and microstructure evolution of as-extruded $7075 \mathrm{Al}$ alloy during hot deformation. Mater. Charact, 90, 71-80. https://doi.org/10.1016/j.matchar.2014.01.019

[21] Wang, M., Jin, P., Wang, J., \& Han, L. (2014). Hot deformation behaviour of as-quenched $7005 \mathrm{Al}$ alloy. Trans. Nonferrous Met. Soc. China, 24, 2796-2804.

https://doi.org/10.1016/S1003-6326(14)63411-7
[22] Chen, L., Zhao, G., \& Yu, J. (2015). Hot deformation behaviour and constitutive modeling of homogenized 6026 Al alloy. Materials \& Design, 74, 25-35. https://doi.org/10.1016/j.matdes.2015.02.024

\section{Contact information}

\section{Xiang ZHANG}

(1) School of Mechatronic Engineering,

China University of Mining and Technology,

Xuzhou, 221116, China

(2) State Key Laboratory of Intelligent Manufacturing of Advanced Construction Machinery, Xuzhou, 221004, China

\section{Xiaoxi WANG}

Corresponding author

School of Mechanical and Electrical Engineering,

Xuzhou University of Technology,

Xuzhou 221018, China

Email:wxx19851109@sina.com

\section{Dekun ZHANG}

School of Mechatronic Engineering

China University of Mining and Technology,

Xuzhou, 221116, China 